titLE THE LOS ALAMOS HIGH-BRIGHTNESS PHOTOINJECTOR

AUTHORIS)

Patrick G. O' Shea

SHHMITIED

Proceedings

Symposilim on High-Brightness Beams

June $6-7,1991$

University of Maryland

College Park, Maryland

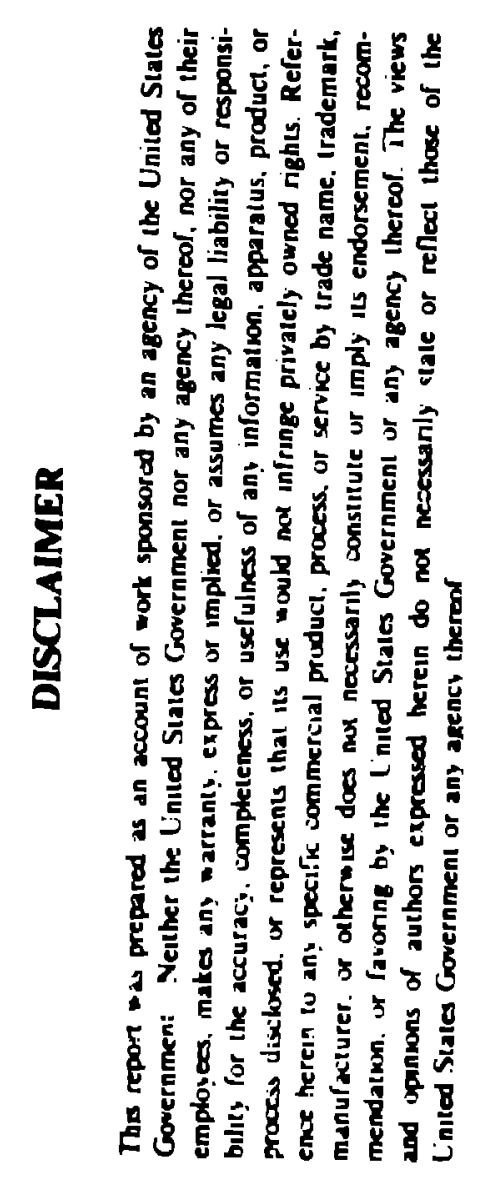

1) $11 ! 1$

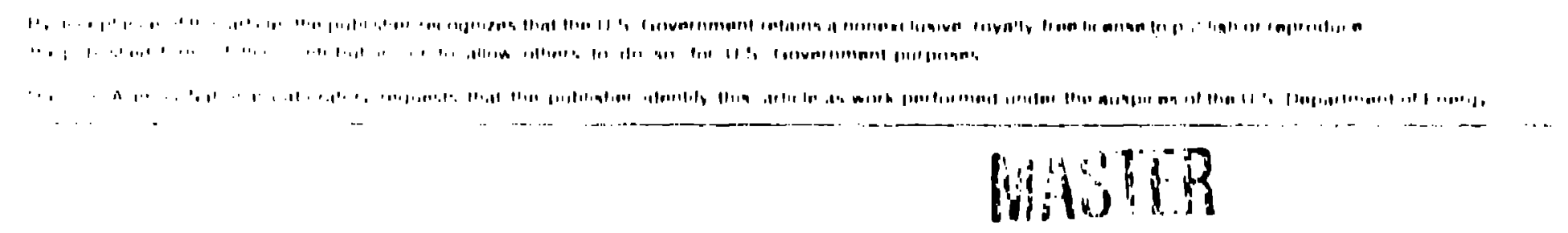

II.(O) A A A 


\title{
The Los Alamos High-Brightness Photoinjector
}

\author{
Patrick G. O'Shea \\ MS J579, Los Alamos National Laboratory, Los Alamos NM 87545
}

\begin{abstract}
For a nuniber of years Los Alamos National Laboratory has been developing photocathode RF guns for high-brightness electron beam applications such as freeelectron lasers (FELs). Previously thermionic high-voltage guns have been the source of choice for the electron accelerators used to drive FELs. The performance of such FELs is severely limited by the emittance growth produced by the stbbhamonic bunching process and also by the low peak current of the source. In a pholoinjector, a laser driven photocathode is placed directly in a high-gradient RF accelerating cavity. A photocathode allows unsurpassed control over the current, and the spatial and temporal profile of the beam. In addition the "electrodeless emission" avoids many of the difficulties associated with multi-electrode guns, i.e. the electrons are accelerated very rapidly to relativistic energies, and there are no electrodes to distort the accelerating fields. For the past two years we have been integraling a photocathods iillo our existing FEL, facility by replacing our thermionic gun and subharmonic bunchers with a high-gradient $1.3 \mathrm{GHz}$ photoinjector. The photoinjector, which is approximately $0.6 \mathrm{~m}$ in length, produces $6 \mathrm{MeV}, 300 \mathrm{~A}, 15$ ps long electron micropulses at a $22 \mathrm{MHz}$ rep. rate. The beam is then injected into an $\mathrm{RF}$ linac, and accelernted to a final energy of $40 \mathrm{MeV}$. We have recently begun lasing all wavelengths near $3 \mu \mathrm{m}$.
\end{abstract}

\section{INITROUCTION}

The efficient conversion of electron energy into photon energy requires low cmiltance, high-brightness beans 1 . Free-el ctron lnser oscillutors operating at high power und short wavelength $\left(\lambda_{0}\right)$ require high-current, low-enitunce $\left(c_{11}\right)$ electron beams. 'The gain of un lilil, increases with beam current subject to the constrnint that

$$
\lambda_{0}>\frac{r_{11}}{4 \pi \mid 3 \gamma}
$$

where $r_{n}-4 \pi \mid \beta \gamma\left(x^{2}><x^{2}>-<x, x^{\prime}>2\right)^{1 / 2}$ is the normilized emittunce. In this context high current implics I" I(K) A and low cmitunce implies $l_{n \text { " } I(K)} \pi$ mm-mrad. Very low emillance nllows the possibility of ncessing short optical wavelengths al low beam energy, hy lasing on harmonics of the fundumenenl fil:l, wavelength. 'The liti, resontunce comdition is given by: 


$$
\lambda_{\mathrm{o}}=\frac{\lambda_{\mathrm{W}}}{2 \mathrm{~N} \gamma^{2}}\left(1+\mathrm{K}^{2}\right)
$$

where: $\mathrm{K}$ is the wiggler parameter typically of order $1, \gamma$ is the relativistic energy parameter, $\lambda_{\mathrm{w}}$ is the wiggler period, $\mathrm{N}$ is the harmonic number with $\mathrm{N}=1,3,5 \ldots$ If the emiltance satisfies the constraint of eqn. 1, then harmonic lasing may be possible at short wavelengths. The electron beam energy required to produce a given wavelength scales as $\frac{1}{\sqrt{N}}$, and produces a corresponding saving in the size and cost of the accelerator required.

There are two issues of importance here. The first is the intrinsic brightness of the sotrce and the second is the ability to transport the beam with minimal emittance growth through the linac.

Previously high brightness beams have been produced by thermionic high-voltage guns, with emittances near the source thermal limit. We can define the normalized emittance for a source in terms of the cathode radius $\left(r_{c}\right)$ and temperature $(T)^{2}$ :

$$
\varepsilon_{n}=2 \pi r c \sqrt{\frac{k T}{m c^{2}}}
$$

and the normalized brightness in terms of the current density J:

$$
B_{n}=\frac{2 I}{\left|E_{n}\right|^{2}}=\frac{m c^{2} J}{2 \pi k T}
$$

Table I shows 11 comparison between the best themionic cathode and photocathode

\begin{tabular}{|c|c|c|}
\hline Cathoule & 'Thermionic & Photocnthode \\
\hline T: Iiflective Iemp. (eV) & 0.1 & 0.2 \\
\hline J: ('urrent density $\left(\Lambda / \mathrm{cm}^{2}\right)$ & 10) & $\sigma(x)$ \\
\hline Brightuess $\left(\Lambda /(m-\text { rad })^{2}\right.$ & $1 \times 10^{11}$ & $2 \times 10^{12}$ \\
\hline
\end{tabular}
sources for Rl' linacs?.

'I'able 1. Comparison of thermionic cuthode and photocuthode

Photeculhogle hus intrinsicully higher brightness and reduced emiltunce growih in transent through the linas. The design of an integrated photoinjector linte removes

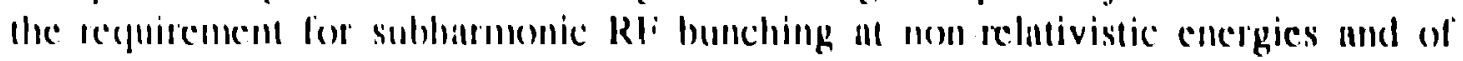


magnetic bunching common in linacs with thermionic sources, thereby removing many of the emittance growth opportunities.

For a number of years we have been developing photocathode RF guns for highbrightness electron beam applicationed In a photoinjector, a laser driven photocathode is placed directly in a high-gradient $R F$ accelerating cavity (see fig. 1). This system allows unsurpassed control over the spatial and temporal profiles, and current of the beam. In addition the "electrodeless emission" avoids many of the difficulties associated with multi-electrode guns,i.e. the electrons are accelerated verv rapidly to relativistic energies, and there are no electrodes to distort the accelerating fields.

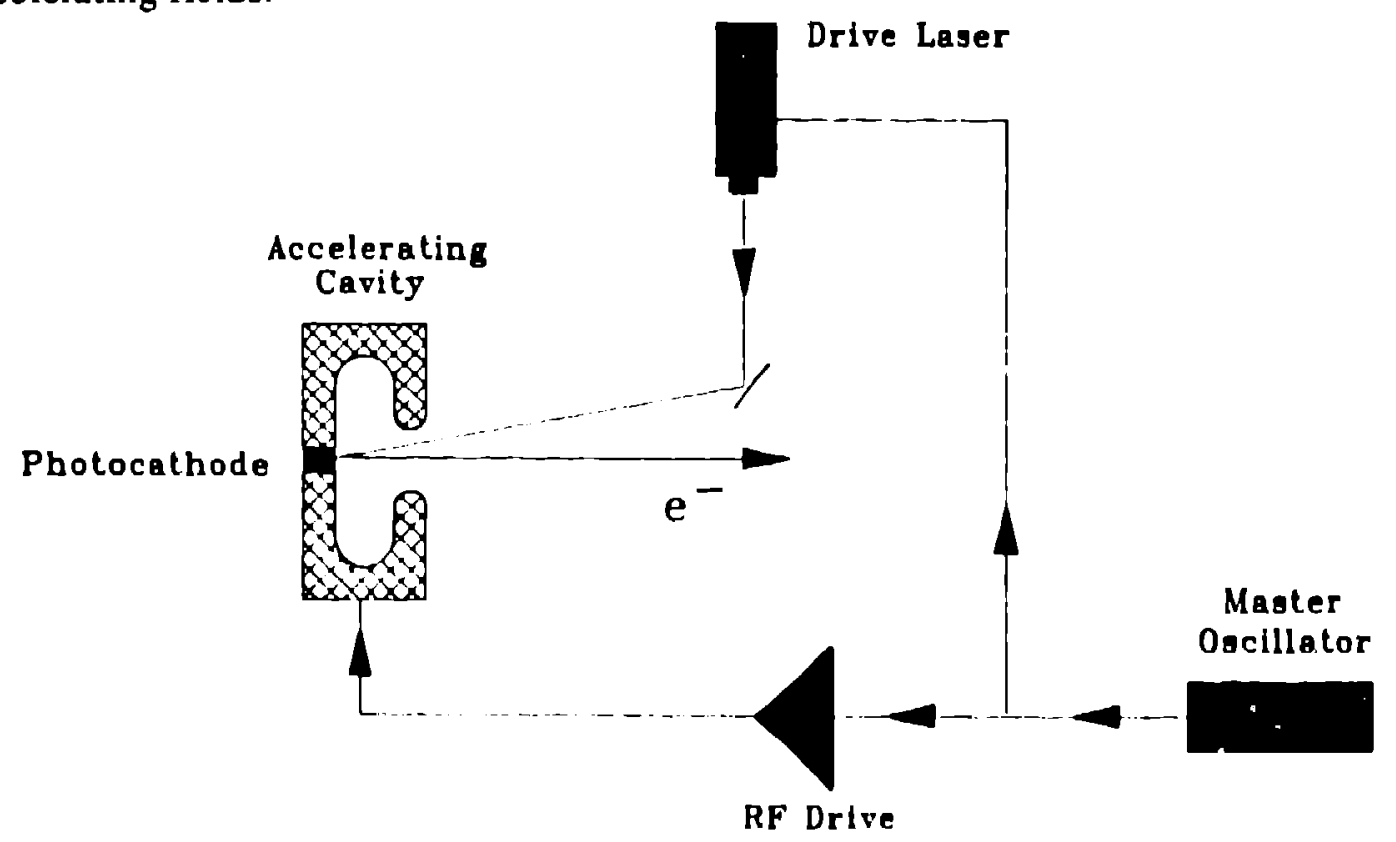

Fig 1 Photoinjector schematic

\section{Drive I,aser and Photocathode}

The re have been a number of approaches proposed for the photocathode/Jrive laser combination necessary for a pholoinjector. 'These appronches are divided ineo (wo classes: I ow yuantum efficiency and high quuntum efficiency. (Qumntum efficiency, Q. is de lined as the number of free electrons produced off the culhode per incident photon). Low Unantum efficiency cathoses $(Q<0.1 \%)$ have typically the following characleristicss-7:

metul or 1 .nth , cullode

long cinhose lifetime

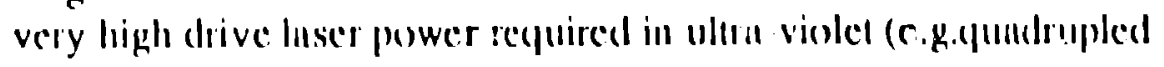

Nol:Y $Y(i)$

not rendily sculable on high rep. rate or duty finctor. 
High Quantum Efficiency Cathodes $(Q>1 \%)$ are characterized by 3 :

multi-alkali(e.g. $\mathrm{CsK}_{2} \mathrm{Sb}$ )

short cathode lifetimes (days)

high $Q$ in the visible

scalable to high duty factor

Following from the definition of quantum efficiency above, we can readily obtain the fundamental relationship between drive-laser wavelength $\left(\lambda_{\mathrm{DL}}\right)$, and pulse energy $(E)$, photocathode quantum efficiency $(Q)$ and charge $(C)$ per pulse is given by:

$$
C=\left[\frac{\mathrm{e}}{\mathrm{hc}}\right] \mathbf{Q E} \lambda_{\mathrm{DL}}
$$

An alternative formulation of this equation is in terms of current (I) from the calhode and drive laser power $(\mathbf{P})$ :

$$
I=\left[\frac{\mathrm{e}}{\mathrm{hc}}\right] \mathbf{Q P} \lambda_{\mathrm{DL}}
$$

Equation (6) is only valid for the case of prompt electron emission from the cathode i.e. the emission time is much less than the drive laser pulse length. Equation (6) may be re written in practical units:

$$
\mathrm{l}(\Lambda)=8.1) 8 \times Q(\%) \times P(\mathrm{~kW}) \times \lambda_{\mathrm{DL}}(\mu \mathrm{m})
$$

In the case of the $L$ os Alamos experiment $I=0.1 \wedge$ (macropulse average), $Q=6 \%$ and $\lambda_{\mathrm{I})}=(0.527 \mu \mathrm{m}$ (doubled $\mathrm{NJ}: \mathrm{YLF}$ ), then $P=4 \mathrm{~W}$. For low quantum efficiency cathodes $Q<\left(0.01 \%\right.$, al $\lambda_{\mathrm{PI}}=0.26 \mu \mathrm{m}$ (quadrupled Nd:YAG), then $P=48(0) \mathrm{W}$ for the same $0.1 \wedge$ macropulse average current. Note that this is the dive laser power actually delivered to the cathode. The low quantum efficiency cuthodes do not appear practical for high nverage current applications because of the high drive laser power required.

At Ios Alamos we have chosen a high $Q$ mmerial CsK $_{2}$ Sh. Typically $Q$ is grenter than 6"\% at the stutt of an accelerntor run. I lowever such cuthodes are sensitive to contanimation in poor vacumm. 'lypically the vacuum in the operating photexithesle (e)l! is less than $1 \times 10^{-9}$ torr. 'The $1 / \mathrm{e}$ lifetime for decilly of $Q$ is grenter than 10 hes

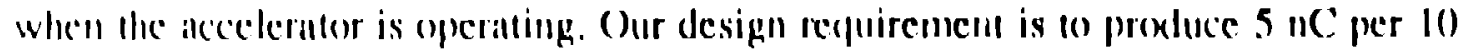

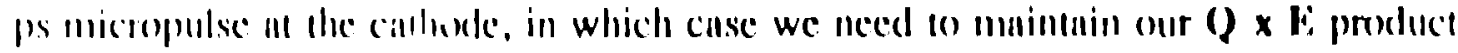

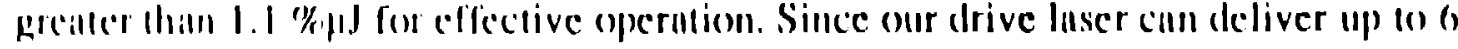

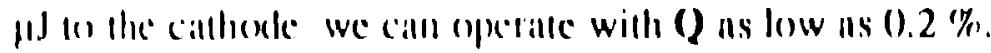

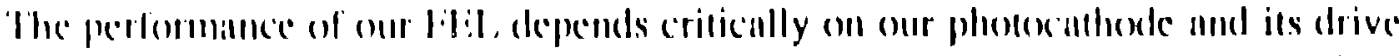
laser. Phase and amplitude jiller in the drive laser result in energy and current jiller 
in the electron beam. We require the phase and amplitude jitter to be $<1$ ps and $<1$ \% respectively. Table 2 gives the measured performance of the drive laser and photocathode.

To improve our operating time on a single cathode we are endeavoring to a) reduce the quantum efficiency decay rate; and $b$ ) increase the energy delivered by the drive laser to the photocathode.

'Table 2 Drive laser and photocathode performance

$\begin{array}{ll}\text { Drive laser: } & \text { Doubled Nd-YLF } \\ \text { Witvelength } & 527 \mathrm{~nm} \\ \text { Micropulse width } & 7-15 \mathrm{ps} \\ \text { Micropulse rep. } & 21.7 \mathrm{MHz} \\ \text { rate } & 12 \mu \mathrm{J}(5-6 \mu \mathrm{J} \text { at } \\ \text { Micropulse } & \begin{array}{l}\text { cathode }) \\ \text { energy }\end{array} \\ \begin{array}{l}\text { Macropulse length } \\ \text { Pliase jitter }\end{array} & 0-20(\mu \mathrm{s} \\ \text { Amplitude jitter } & <1 \% \\ & <1 \% \mathrm{ps} \\ \text { Photocathode: } & \mathrm{CsK} 2 \mathrm{Sb} \\ \text { Radius } & 4-5 \mathrm{~mm} \\ \text { Peak quantum } & 8 \% \\ \text { efficiency } & \\ \text { 1/e lifetime in } & 10-15 \mathrm{hrs} \text { at } 2 \times 10^{-9} \\ \text { operating } & \text { Torr } \\ \text { accelerator } & \end{array}$

Reducing the decay rate of $Q$ implies improving the vacuum conditions in the accelerator. Studies have shown that $\mathrm{CO}_{2}$ and $\mathrm{H}_{2} \mathrm{O}$ can contaminate the cathode and reduce its effective lifetime 8 . Since a stundard bake $n$ 25()-350 $0^{\circ} \mathrm{C}$ imparts a 1 eV o surfice adsorbed niolecules, it is not effective in removing those ndsorbed gases that are bound with hinding energies $" 1 \mathrm{eV}$. In the non-operating accelerator (IIo RI, no beam) such a buke produces a vacuum of $5 \times 10^{-10}$ (orr. In the operating accelerator there are many elecirons with energies n $1 \mathrm{cV}$ that induce electron stimulated (lesorption (liSi)) of gases from the cavity walls and cause the pressure to rise (0) the mid 1()$^{-9}$ (orr range. To improve this situation we have initinted an RI: gencraled glow discharge cleaning rechnique9. Using 2(x) W C.W 1.3 (illz RI, fed inta) the photoinjector cavily through the whveguide, we generated a glow discharge with approximalely I0 2 Ior of hyclrogent. By varying the Rl: frepuency (1.3 10.0 .3 (ill, ) he plow coukl be initialled in one or more cells of the photoinjector. I )uring

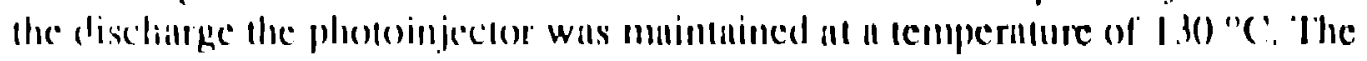


discharge was run for 48 hours, followed by a 24 hour bake at only $130^{\circ} \mathrm{C}$. The immediate result was to reduce the pressure to $1 \times 10^{-10}$ torr at room temperature. Preliminary results indicate that the pressure during high power RF operation has becn reduced to the low $10^{-9}$ torr range.

We have implemented a drive laser upgrade which has increased the deliverable optical energy to the photocathode from 1 to $6 \mu \mathrm{J}$ per micropulse.

At present we have a single cathode which must be refurbished when its $Q$ falls below allowable limits. This refurbishment process involves retraction of the cathode into a preparation chamber and the bake-off of the residual cathode material that is only a few tens of nanometers thick, followed by the redeposition of the cathode material. This process takes about 3 hours. So as to reduce this downtime we plan to replace the single cathode system vith a six-cathode casette. These cathodes will be fabricated awny from the accelerator and brought to the accelerator in a portable vacuum chenber. When this system is in place we will not need a preparation chamber attached to the accelerator. The accelerator runtime between casette changes should be in excess of a week.

\section{The APEX Photoinjector}

We have installed and tested a high-gradient (26 MV/m at the cathode) 1300 $\mathrm{MIz}, \pi / 2$-mode photoinjector, that is $0.6 \mathrm{~m}$ long and produces $6 \mathrm{MeV}, 300 \mathrm{~A}, 15 \mathrm{ps}$ electron pulses at a $22 \mathrm{Mllz}$. rep. rate ${ }^{10}$ Figure 2 shows a cutaway view of the actual Los Alamos $6 \mathrm{MeV}$ photoinjector. Table 3 gives the specifications for the photoinjector. The photocathode cell is a half cell, followed by five full accelerating cells. The RF feed is through the sixth cell. The accelerating cells are coupled by on axis coupling cells. The RF structure is enclosed in a stainless steel vacium jacket, in which are attached a titanium sublimation pump and an ion pump. Pumping from the accelerating ce!ls into the vacuum manifold is achieved through 16 longitudinal slots per ell, giving an effective pumping speed of approximately $170 \mathrm{l} / \mathrm{s}$ per cell. The resultant pressure at the photociuhode is typically less than $10^{-9}$ torr. The photocithode itself is on a molybdenum plug that is attached to an actuator. The cathoste can be retracted from the accelerator into the photocathode preparation chatmiber.

following the photoinjector electron benm is nccelernted to $40 \mathrm{MeV}$ by three additional side-compled linic lanks. RP power is provided by Thomson CSF

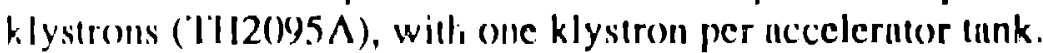

The lilit, configuration is a single-accelerator master-oscillator power-amplifier (SAM()PA, 11-1.3 configuration. Resonator optics are often the limiting factor in high average power blas. In the $\$ \wedge M() \mid>$ concept the electrons first pass through a low power oscillaner and then lhrough a high gain amplifier. The light from the oscillater is fed into dhe implifier. Since the power in the oscillator is low, and there: atre no resommer optics in the amplifier, the optical demuge difficulty is removed. We are studying the physies issues ussexinted with SAMOPA operation as part of 
the Boeing/Los Alamos collaboration to build the Average Power Laser Experiment (A!'LI). Los Alumos will perform the $\Lambda P I J$ prototype experiments and will be known by the acronym APEX.

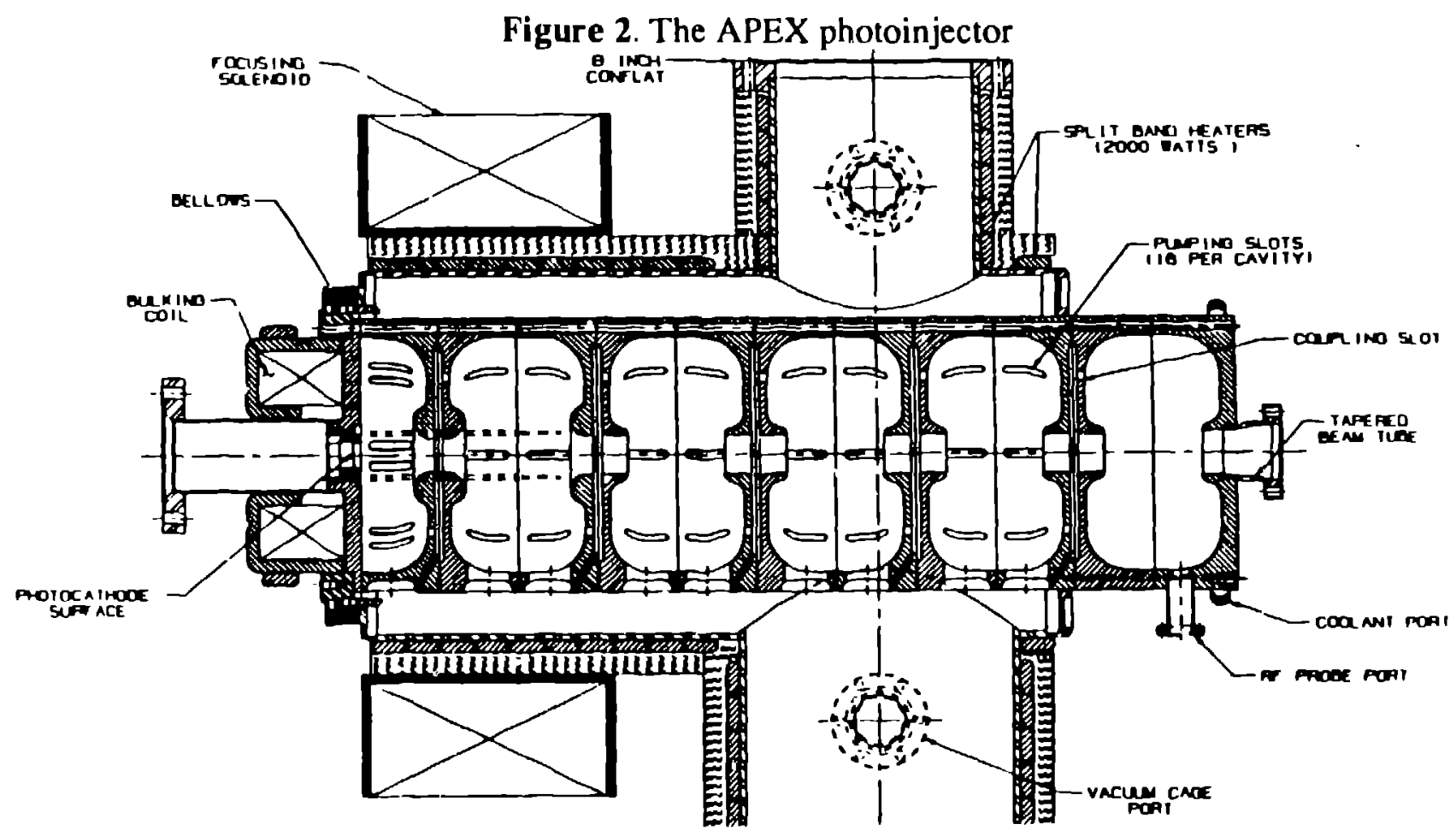

'Table 3 Photoinjector specifications

Frequency

Accelerating gradients:

cell 1

cell 2

Measured Q cell 3-6

Shunt impedance

Copper power

Output energy

Micropulse length

Micro pulse charge

Micropulse rep. rate

Peik current

Macropulse length

Macropulse rep. rnte

Macropulse ave. current

fimillitice (4rms, normalized)
$1300 \mathrm{MHz}$

26.0 MV/m

$14.4 \mathrm{MV} / \mathrm{m}$

$10.0 \mathrm{MV} / \mathrm{m}$

18500

$35 \mathrm{M} \Omega / \mathrm{m}$

$1.8 \mathrm{MW}$

$6 \mathrm{MeV}$

$15 \mathrm{ps}$

$5 \mathrm{nC}$

$21.7 \mathrm{MHz}$

$3(x) A$

$1(K) \mu \mathrm{s}$

$111 z$

$0.1 \wedge$

$<5() \pi \mathrm{mm}-\mathrm{mrnd}$ 
In 1990 we completed experiments that characterized the photoinjector operation and beam transport through one additional accelerator tank at an energy of $15 \mathrm{MeV}$

\section{RF Controls}

The stability of the RF phase and amplitude is as critical to the FEL performance as is that of the drive laser. We have replaced our old RF feedback control system with a novel system using state-feedback 14 . The system in its present form is significantly smaller and produces better RF stability than our old system. Table 3 gives the performance of the state-feedback systam over a 100 - $\mu$ s macropulse on the photoinjector.

Table 4 RF phase and amplitude stability

\begin{tabular}{|l|c|c|}
\hline & $\begin{array}{l}\text { Amplitude } \\
(\%)\end{array}$ & Phase (ps) \\
\hline Jitter & 0.03 & 0.1 \\
\hline Siew & 0.25 & 1 \\
\hline
\end{tabular}

We have recently testing the effectiveness of the feedback system on all four accelerator tanks.

\section{Operational Experience}

Measurements on the electron beam produced by the photoinjector have been made after post acceleration to $14 \mathrm{MeV}$ by an additional side coupled tank. Of particular interest has been the comparison between the design code (INEX) predictions and actual performance. Details of the comparison between INEX and measurements have been presented elsewhere 15 .

The performance of the photoinjector has proven to be excellent in the areas of most importance to FliL operation, i.c. reduced emittance and reduced energy spread and increased brightness as indicated in table 5 .

T'able 5 Comparison of the performance of the old vs. new injector at the Los Alamos FEL

\begin{tabular}{|l|c|c|}
\hline Electron source & Thermionic gun & Photoinjector \\
\hline I:mitlance & $160 \pi$ mm-mrad & $40 \pi$ r.mm-mrid \\
\hline Energysgread & $0.5 \%$ & $0.3 \%$ \\
\hline C'hirge per bunch & $5 \mathrm{nC}$ & $5 \mathrm{nC}$ \\
\hline Peilk Current & $3(x) \Lambda$ & $3(00 \Lambda$ \\
\hline
\end{tabular}




\begin{tabular}{|l|l|l|}
\hline Brightness & $2.4 \times 10^{9} \mathrm{~A} /(\mathrm{m}-\mathrm{rad})^{2}$ & $4 \times 10^{10} \mathrm{~A} /(\mathrm{m}-\mathrm{rad})^{2}$ \\
\hline
\end{tabular}

There were three unanticipated effects observed during operation of the photoinjector:

1)Multipactoring in one or more coupling cells produced coherent $7 \mathrm{MHz}$ oscillations in both phase $\left( \pm 1^{\circ}\right)$ and amplitude $( \pm 1 \%)$ of the RF in the tank. The problem was solved by detuning the photocathode cell (the end wall was pulled by a couple of tenths of $\mathrm{mm}$ ) so as to raise the fields in the coupling cells above the multipactoring limit.

2) The electron beam was observed to have an clliptical crossection before passing through any quadrupole magnets. The soirce of this effect was RF quadrupole focusing resulting from the number and location of the coupling slots in the accelerator.This has caused an emittance growth of approximately $10 \pi \mathrm{mm}$ mirad. This problem is being partially corrected by placing a small quadrupole magnet between the photoinjector and the next tank. Future photoinjector designs will have a modified coupling slot arrangement which will eliminate this emittance growth problem. For more details see ref. 15.

3) A small field-emission electron current $(0.1 \mathrm{~mA})$ was observed with the drive laser off. The intensity of this field emission current is not sufficient to significantly affect our operation. For more details see ref. 16

\section{Present Status}

The commissioning of the complete $40 \mathrm{MeV}$ linac with the integrated photoinjector is complete. On June 21, 1991 first lasing was observed at a wavelength of $3.5 \mu \mathrm{m}$ with an extraction efficiency of $0.6 \%$ over a 40 is macropulse. We are continuing to characterize the accelerator and FEL performance. Details of the designed performance of the FEL system are given in ref. 3 .

\section{Conclusion}

We have shown in practice that phocathodes integrated into RF linac in the form of photoinjectors are a viable and practical alternative to thermionic sources. In the Ios Alamos case replacing the thermionic gun and subharnionic bunchers with a phiotevinjector has increased the electron heam brightness by a factor of 20 . We helieve that high cutuntum efficiency cathodes are the only practical choice for high average current electron accelerators because the drive laser power is prohibitively high for low guantum efficiency sources. The present disadvantage of high quantum efficiency sources is the relatively short cathode lifetime. We have made significint progress in understanding the cathole decay processes and in improving the lifetime. We comlinue to work on more advanced cathode designs that will lead us on botls high cuantum efficiency and long lifetimes. Based on our experience with the APEX 
photoinjector we are constructing new $20 \mathrm{MeV}$ photoinjector as part of the Advanced FEL (AFEL) project. The electron beam from the AFEL accelerator should be an order of magnitude brighter than that of APEX.

\section{Acknowledgements}

This work was supported and funded by the US Department of Defense, Army Stralegic Defense Command, under the auspices of the US Department of Energy. The successful operation of the APEX free-electron laser was made possible through the efforts of a large number of dedicated people. The following deserve special recognition for outstanding contributions to the project: $K$. McKenna and $R$. Shefficld for overall project guidance; D. Feldman for accelerator and FEL commissioning; B. Carlsten, J. Goldstein and M. Schmitt and B. McVey for theoretical support; D. Schrage and L. Young for the design and construction of the photoinjector; N. Okamoto, P. Schafstall R. Springer and S. Volz for the pholocathode subsystem;G. Busch, J. Barton and J. Early for the photocathode drive laser, L. Connor, J. Johnson, N. Okay, P. Ortega, W. Stein and T. Zaugg for : he RF system, S. Apgar, R. Feldman and A. Lumpkin for electron bean diag : and data analysis; S. Bender, D. Byrd, M. Feind N. Okamoto for FEL res snator and optics; R. Martinez and R. Stockley for mechanical support

\section{References}

1. For an introduction to FEL physics see "Free-Electron Lasers" by C.A. Brau, in Advances in Electronics and Electron Physics, Suppliment 22,Academic Press (San Dieg()), (199()).

2. For discussion of emittance and brightness see "The Physics of Charge-Particle Beams" 2nd ed. by J.D. Lawson, Clarendon Press (Oxford), (1988)

3. R.L Sheffield, "Photocathode RF Guns", in Physics of Particle Accelerators, vol 2, AIP Conference Proc. \#184, pgs 15:)()-1531.

4. R.L. Sheffield, E.R. Gray, J.S. Fraser "The Los Alamos Photoinjector Program" Nucl. Inst. Meth. A272 222, (1988)

5. M. Curtin, G. Bennett, R. Burke, A. Buwmik, P. Metty, S Benson, J.M.J. Madey, Nucl. Inst. Meth, A296,127, (1990)

6. S. Ilarmin et. al to appear in the Proc. 1991 IEEE Particle accelerator Conf.

7. K. Batchelor, Proc. 1990 Linear Accelerator Conf., p. 810, Los Alamos publication L.A-12(X)4-C (1991) 
8. R.L. Sheffield, Proc. 1990 LiNAC Conf., p. 269, Los Alamos Pub. \# LA-12004C (1991)

9. "Surface Conditioning of Vacuum Systems", R. Langley Ed., American Vacuum Soc. Series, Vol. 8, AIP, (1990)

10. L.M. Young, Nucl. Inst. Meth., B56/57, 978, (1991)

11. D.W Feldman, W.D. Comelius, S.C. Bender, B.E. Carlsten, P.G. O'Shea, R.L Shaffield, Free-Electron 'asers and Applicaiions, D. Prosnitz, Ed., Proc. SPIE 1227, 2. (1990)

12. B.E. Carlste.., L.M. You.1g, M.E. Jc. nes, B. Blind, E.M. Svaton, K.C.D. Chan, L.E. Thode, Nucl. Inst. Meth., A296, 687, (1990)

13. J.C. Goldstein, B.E. Cirlsten, B.V. McVey, Nucl. Inst. Meth., A296, 273, (1990)

14. W.J.D. Johnson, C.T. Addallah, Proc. 1990 LINAC Conf. page 487 (1991)

15 B.E. Carlsten, L.M. Young, M.J. Browman,"Comparison of INEX Simulations and Experimental Measurements at the Los Alamos FEL Facility", Proceedings of the 1991 Particle Accelerator Conference, to be published.

16. A.H. Lumpkin, "Observations on Field-Emission Electrons from the Los Alamos FEL Photoinjector", Proceedings of the 1991 Particle Accelerator Conference, to be pujlished 